\section{Eosinophil-mediated Injury to Lung Parenchymal Cells and Interstitial Matrix

\author{
A Possible Role for Eosinophils \\ in Chronic Inflammatory Disorders \\ of the Lower Respiratory Tract
}

W. Bruce Davis, Gerald A. Fells, Xiu-Hong Sun, James E. Gadek, Alain Venet, and Ronald G. Crystal Pulmonary Branch, National Heart, Lung, and Blood Institute, Bethesda, Maryland 20205 bstract. Eosinophils are a common component of the inflammation of the lower respiratory tract that characterizes the interstitial lung disorders. Bronchoalveolar lavage analyses $(n=680)$ of 251 patients with interstitial lung disease demonstrated that eosinophils represented $>5 \%$ of the effector cells comprising the alveolitis in $20 \%$ of all lavages. In contrast, lavage of normal individuals $(n=117)$ showed that eosinophils were never $>5 \%$ of the total effector cells recovered. To evaluate a possible role for eosinophils in mediating some of the cellular and connective tissue matrix derangements of the lung parenchyma found in interstitial disease, eosinophils were evaluated for the presence of proteases capable of cleaving connective tissue proteins found in the lung and for the ability to mediate cytotoxicity to lung parenchymal cells. Evaluation of guinea pig and human eosinophils demonstrated that eosinophil granules contained a collagenase that specifically cleaved human collagen types I and III, the two major connective tissue components of the human lung parenchyma. In contrast, the eosinophil did not contain an elastase or a nonspecific neutral protease. The eosinophil collagenase appeared to be a metalloprotease, as it was inhibited by ethylenediamine-

Dr. Davis's and Dr. Gadek's present address is Pulmonary Division, Department of Medicine, Ohio State University, Columbus, OH 43210; Dr. Sun's present address is Department of Physiology, Hunan Medical College, Changsha, Hunan, People's Republic of China; Dr. Venet's present address is INSERM U 214, Hospital Laennec, 74007 Paris, France. Address reprint requests to Dr. Crystal, Room 6D06, Building 10, National Institutes of Health, Bethesda, MD 20205. 1984.

Received for publication 15 August 1983 and in revised form 5 March

J. Clin. Invest.

(C) The American Society for Clinical Investigation, Inc. 0021-9738/84/07/0269/10 $\$ 1.00$

Volume 74, July 1984, 269-278 tetraacetate but not by phenylmethanesulfonyl-fluoride or $\alpha 1$-antitrypsin. The eosinophil also has the capacity to injure lung parenchymal cells. Without further stimulation, eosinophils purified from peritoneal exudates of guinea pigs demonstrated spontaneous cytotoxicity for human lung fibroblasts (HFL-1), cat lung epithelial cells (AK-D) and rat lung mesothelial cells (I6B). Under identical conditions, the epithelial cells were more sensitive to eosinophil-mediated cytotoxicity than the fibroblasts or mesothelial cells $(P<0.01)$, consistent with the clinical observation that in the interstitial disorders, the alveolar epithelial cells are damaged more commonly than fibroblasts or pleural cells. The eosinophil-mediated cytotoxicity could be partially inhibited by the antioxidants catalase and dimethylsulfoxide suggesting that toxic oxygen radicals play a role in mediating the cellular damage. Importantly, eosinophils purified from bronchoalveolar lavage of human interstitial lung disease also demonstrated spontaneous cytotoxicity for lung epithelial cells. These observations demonstrate that eosinophils are frequent participants of the alveolitis of the interstitial lung disorders and suggest that these cells have the potential to damage the parenchymal cells and collagen matrix of the lower respiratory tract.

\section{Introduction}

In the normal lung, the eosinophil is found in the mucosa of the upper airways, where it is thought to play an important role in dampening immediate hypersensitivity reactions $(1,2)$. In contrast, in the lower respiratory tract, eosinophils are rare (35). However, when there is inflammation in the lower respiratory tract, as is found in the interstitial lung disorders, morphologic $(6-8)$ and bronchoalveolar lavage $(3,4,9,10)$ data suggest that eosinophils can accumulate in the alveolar structures and occasionally in the pleural tissues (8).

The role of the eosinophil in this inflammation is unclear. 
However, since the interstitial lung disorders are characterized by injury to the cells and connective tissue matrix comprising the lung parenchyma, it is reasonable to hypothesize that eosinophils may play some role in the derangements of the lower respiratory tract that accompany these disorders. Support for such a concept comes from the knowledge that while the eosinophil is generally considered to be a "beneficial" cell that suppresses mediators of inflammation, there is increasing evidence that the eosinophil may also be able to damage normal tissues. First, eosinophils have the potential to damage parasites such as Shistosoma mansoni $(11,12)$ and Trichinella spiralis (13); presumably, if eosinophils can injure such relatively hardy organisms, the eosinophil likely has the potential to injure normal tissues. Second, eosinophils carry major basic protein $(14,15)$, a highly toxic polypeptide that under appropriate circumstances can clearly damage normal tissues such as tracheal mucosa (1618). Third, eosinophils can damage normal cells through antibody-dependent cytotoxic processes $(19,20)$. Fourth, eosinophils can release toxic oxygen radicals (21) and contain a peroxidase that can generate halide-related oxidants $(22,23)$. Fifth, in the hypereosinophilic syndrome there is accumulation of eosinophils in tissues that is paralleled by organ injury (24).

In this context, the present study was designed to evaluate a role for eosinophils in mediating some of the injury to the lung parenchyma in the interstitial lung disorders. To approach this concept we have examined three questions. First, what is the extent to which eosinophils contribute to the alveolitis of these disorders i.e., how frequently do eosinophils accumulate in the lower respiratory tract in these disorders and to what magnitude? Second, do eosinophils have the potential to damage major connective tissue components of the alveolar wall? Third, do eosinophils have the potential to injure lung parenchymal cells? The results demonstrate that eosinophils are commonly present, often to a surprising degree, and that they have the potential to damage the major interstitial collagens as well as lung parenchymal cells.

\section{Methods}

Frequency and extent of eosinophils contributing to the inflammation in interstitial lung disease. To evaluate the frequency and magnitude of the eosinophil contribution to the alveolitis of the interstitial lung diseases, the cell differentials of 680 consecutive bronchoalveolar lavages of 251 patients with interstitial disease were evaluated for the presence of eosinophils. The study group was comprised of patients with various interstitial disorders evaluated by the Pulmonary Branch, National Heart, Lung and Blood Institute over a 5-yr period. These disorders included idiopathic pulmonary fibrosis (IPF;' 90 patients, 292 lavage analyses), sarcoidosis ( 98 patients, 278 lavages), hypersensitivity pneumonitis (12 patients, 20 lavages), chronic interstitial lung disease associated with the

1. Abbreviations used in this paper: $\mathrm{CDVx}$, collagen-vascular disorders; ECF-A, eosinophil chemotactic factor; EPx, eosinophilic pneumonia; HBSS, Hanks' buffered saline solution; HyPx, hypersensitivity pneumonitis; HX, histiocytosis-X; IPF, idiopathic pulmonary fibrosis; PMA, phorbol myristate acetate; PMSF, phenylmethanesulfonylfluoride. collagen-vascular disorders ( 23 patients, 35 lavages), histiocytosis-X (20 patients, 41 lavages) and chronic eosinophilic pneumonia (8 patients, 14 lavages) (25). Patients were excluded from the study if they had evidence of allergy or infection of the upper respiratory tract. For comparison, the cell differentials of consecutive lavages of 117 normal individuals (each evaluated once only) were evaluated for the presence of eosinophils.

Bronchoalveolar lavage was carried out in patients and normal individuals using previously described methods $(3-5,10)$. After bronchoalveolar lavage the recovered fluid was centrifuged $(600 \mathrm{~g}, 15 \mathrm{~min})$ to separate cellular and noncellular constituents. The cells were resuspended in RPMI-1640 medium (Gibco Laboratories, Grand Island, NY) and a small aliquot was used to prepare modified Wright-Giemsa-stained cytocentrifuge slides from which lavage cell differentials were determined. A minimum of 200 cells were evaluated in all cases.

Source and purification of eosinophils. Eosinophils were obtained from three sources, the guinea pig peritoneum, human blood, and human lung. Because of difficulties in obtaining large numbers of purified human eosinophils, guinea pig eosinophils were used for all studies except as indicated.

To obtain guinea pig eosinophils, female National Institutes of Health (NIH) strain guinea pigs weighing $300-400 \mathrm{~g}$ were stimulated by weekly intraperitoneal injections of polymyxin B sulfate (Sigma Chemical Co., St. Louis, MO; $1 \mathrm{mg}$ in $1 \mathrm{ml} 0.9 \%$ saline) and by weekly saline peritoneal lavages as described by Pincus (26), and Gleich and Loegering (27). The saline peritoneal lavage was accomplished by injecting $100 \mathrm{ml}$ of saline into the peritoneum and allowing it to passively drain through a 14gauge polyethylene catheter (Deseret Co., Sandy, UT). After 4 wk of dual stimulation by polymyxin B and peritoneal lavage, all animals developed an intense peritoneal inflammation comprised of $\sim 50 \%$ eosinophils and $50 \%$ mononuclear cells. Peritoneal washings from these animals were centrifuged $(500 \mathrm{~g}, 15 \mathrm{~min})$ to separate cellular and noncellular components. The cells were washed in Hanks' balanced salt solution without $\mathrm{Ca}^{++}$and $\mathrm{Mg}^{++}$(HBSS) and the eosinophils and mononuclear cells separated by density gradient centrifugation (27). To accomplish this, the recovered lavage cells were resuspended in $10 \mathrm{ml}$ HBSS, underlayered with $10 \mathrm{ml}$ of sodium diatrizoate solution (Sigma Chemical Co. $)(d=1.142 \mathrm{~g} / \mathrm{ml})$, and centrifuged $\left(600 \mathrm{~g}, 40 \mathrm{~min}, 4^{\circ} \mathrm{C}\right)$. The eosinophil-containing pellet was washed, counted by hemocytometer, and evaluated for purity by differential cell count of a cytocentrifuge preparation. A total of 34 guinea pigs were used an average of 25 times each. An average of $11.8 \pm 1.0 \times 10^{6}$ eosinophils $(97.0 \pm 0.3 \%$ pure $)$ were obtained from each animal at each peritoneal lavage. In no experiments were the eosinophil preparations $<91 \%$ pure. The principal contaminating cells were mononuclear cells; neutrophils comprised $<0.5 \%$ of the differential in all experiments.

To evaluate the effector functions of human blood eosinophils, heparinized blood was obtained from an asymptomatic 37-yr-old male with idiopathic hypereosinophilic syndrome (77\% eosinophils). The blood was sedimented with plasmagel (HTI Corp, Buffalo, NY) to remove erythrocytes and the leukocyte-rich fraction was subjected to HypaqueFicoll density gradient centrifugation to remove mononuclear cells (28). The pelleted cells were washed and treated with $150 \mathrm{mM} \mathrm{NH}_{4} \mathrm{Cl}$ and $10 \mathrm{mM} \mathrm{KHCO}_{3}$ to remove contaminating erythrocytes. The resulting population consisted of $91 \%$ eosinophils and $9 \%$ neutrophils.

Eosinophils were obtained from the lung of a 45-yr-old female with chronic eosinophilic pneumonia with a known eosinophil-macrophage alveolitis (lavage cell differential $43 \%$ eosinophils, $56 \%$ alveolar macrophages, $1 \%$ neutrophils). To obtain sufficient eosinophils for evaluation, lavage was carried out with a total of $300 \mathrm{ml}$ saline (five, 20-ml aliquots 
in each of three lobes). The eosinophils were purified by Hypaque-Ficoll density gradient centrifugation as described for the blood eosinophils. The resulting pellet consisted of $94 \%$ eosinophils and $6 \%$ alveolar macrophages.

Preparation of eosinophil granule extract. To prepare eosinophil granule extract, 1-2 $\times 10^{8}$ purified eosinophils were suspended in $2 \mathrm{ml}$ of $0.34 \mathrm{M}$ sucrose with $2,000 \mathrm{U}$ sodium heparin and were repeatedly and vigorously pipetted through an 18-gauge spinal needle. WrightGiemsa-stained cytocentrifuge slides were used to monitor the lysis of eosinophils and the separation of granules from cell membranes. Disrupted cell membranes were removed from the opalescent preparation by centrifugation $\left(400 \mathrm{~g}, 10 \mathrm{~min}, 4^{\circ} \mathrm{C}\right)$. The resulting supernate was transferred to another tube and centrifuged $\left(20,000 \mathrm{~g}, 1 \mathrm{~h}, 4^{\circ} \mathrm{C}\right)$. The granule-containing pellet was suspended in $1 \mathrm{ml} 0.34 \mathrm{M}$ sucrose- $1 \mathrm{M}$ $\mathrm{NaCl}$ and frozen at $-20^{\circ} \mathrm{C}$. The frozen granules were thawed, sonicated over ice for $30 \mathrm{~s}$, and centrifuged $\left(20,000 \mathrm{~g}, 30 \mathrm{~min}, 4^{\circ} \mathrm{C}\right)(14,15)$. The supernates were stored in liquid $\mathrm{N}_{2}$ vapor until use. To ensure that this material contained eosinophil granular contents, the supernates were assayed for peroxidase activity (29).

As a control for the protease studies, neutrophil granule extract was prepared using $\sim 2 \times 10^{9}$ human peripheral blood neutrophils $(30)$. The neutrophils were suspended in $10 \mathrm{ml}$ of 0.34 sucrose-heparin solution and repeatedly pipetted through an 18-gauge spinal needle. Disrupted cell membranes were removed by centrifugation $\left(400 \mathrm{~g}, 10 \mathrm{~min}, 4^{\circ} \mathrm{C}\right)$. The resulting supernates were transferred to another tube and centrifuged $\left(48,000 \mathrm{~g}, 1 \mathrm{~h}, 4^{\circ} \mathrm{C}\right)$. The granule-containing pellet was suspended in $10 \mathrm{ml} 0.34 \mathrm{M}$ sucrose-1 $\mathrm{M} \mathrm{NaCl}$ and sonicated over ice for $30 \mathrm{~s}$. Disrupted granular membranes were removed by centrifugation $(48,000 \mathrm{~g}, 1 \mathrm{~h}$, $4^{\circ} \mathrm{C}$ ) and the supernates stored in liquid $\mathrm{N}_{2}$ vapor until use.

Assays for connective tissue-specific proteases. To evaluate the eosinophil granule extracts for the presence of connective tissue-specific proteases, the extracts were first dialyzed against $200 \mathrm{mM} \mathrm{NaCl}, 30 \mathrm{mM}$ Tris, $5 \mathrm{mM} \mathrm{Ca}^{++}, \mathrm{pH} 7.4$. Elastase activity was quantified as the amount of radioactive material released from $\left[{ }^{3} \mathrm{H}\right]$ elastin at $37^{\circ} \mathrm{C}, 18 \mathrm{~h}(31)$. Nonspecific neutral protease activity of eosinophil granule extract was measured as the amount of radioactive material released from $\left[{ }^{14} \mathrm{C}\right]$ globin at $37^{\circ} \mathrm{C}, 18 \mathrm{~h}(32)$. As a positive control for these protease assays, human neutrophil granule extracts were similarly dialyzed and assayed for the presence of elastase and nonspecific neutral protease activity.

Type I and type III collagenase activity was assayed as previously described $(33)$. $\left[{ }^{3} \mathrm{H}\right]$-labeled type I and type III collagens were produced from cultured human fetal lung fibroblasts (HFL-1, American Type Tissue Culture Collection CCL 153). To test for the presence of active collagenase, eosinophil granule extract $(100 \mu \mathrm{l})$ was incubated with the labeled collagen for $18 \mathrm{~h}, 22^{\circ} \mathrm{C}$. The reaction products were ethanol precipitated and analyzed by SDS-polyacrylamide gel electrophoresis and autoradiography. To test for the presence of latent collagenase activity, eosinophil granule extract was treated with trypsin $(250 \mu \mathrm{g} / \mathrm{ml}$, $30 \mathrm{~min}$ ) followed by trypsin inactivation by an excess of soybean trypsin inhibitor $(500 \mu \mathrm{g} / \mathrm{ml}, 30 \mathrm{~min})$. To establish the inhibitory profile of eosinophil collagenase, the effects of eosinophil granule extract on type I and type III collagen were studied in the presence of $10 \mathrm{mM}$ ethylenediaminetetraacetate (EDTA), $1 \mathrm{mM}$ phenylmethanesulfonylfluoride (PMSF), and $5 \mu \mathrm{M} \alpha 1$-antitrypsin.

Cytotoxic effector function of eosinophils. The ability of eosinophils to injure normal lung parenchymal cells was tested by using a conventional cytotoxicity assay (34). Three cell targets were used, human fetal lung fibroblasts (HFL-1), feline lung epithelial cells (AK-D), and rat pleural mesothelial cells (I6B). HFL-1 cells are typical diploid human lung fibroblasts derived from the lung parenchyma of a 16-wk fetus
(35). AK-D cells are a diploid alveolar epithelial line derived from a late stage feline lung (36). I6B cells are a diploid mesothelial cell line derived from rat lung pleura (the kind gift of M. C. Jaurand and J. Bignon, INSERM U139, Creteil, France) (37). All cells were maintained in $10 \mathrm{ml}$ of Dulbecco's Minimum Essential Medium (Biofluids) with $10 \%$ fetal calf serum, $100 \mathrm{U} / \mathrm{ml}$ penicillin, $100 \mu \mathrm{g} / \mathrm{ml}$ streptomycin, and $0.06 \%$ glutamine in $100-\mathrm{mm}$ plastic petri plates (Falcon Labware, Div. Becton, Dickinson, \& Co., Rutherford, NJ) in air, $10 \% \mathrm{CO}_{2}$ at $37^{\circ} \mathrm{C}$. Confluent cells were labeled with $300 \mu \mathrm{Ci}\left[{ }^{3} \mathrm{H}\right]$ uridine (Amersham Corp., Arlington Heights, IL) for $18 \mathrm{~h}$, washed with phosphate-buffered saline (PBS, Biofluids), and gently removed from the plates with $0.25 \%$ trypsin $\left(1.5 \mathrm{ml}, 2 \mathrm{~min}, 37^{\circ} \mathrm{C}\right)$. The cells were then washed four times with HBSS and were counted by hemocytometer.

To quantify eosinophil-mediated cytotoxicity, the eosinophils (>95\% viable by trypan blue dye exclusion) were adjusted to $10^{7}$ cells $/ \mathrm{ml}$ and the target cells to $2.5 \times 10^{5}$ cells $/ \mathrm{ml}$ in RPMI- 1640 with $10 \%$ heatinactivated fetal calf serum. Spontaneous cellular cytotoxicity was determined by incubation of effector cells $\left(10^{6}\right)$ with $2.5 \times 10^{4}\left[{ }^{3} \mathrm{H}\right]$ uridinelabeled target cells; the effector-to-target cell ratio was 40:1 in all studies, unless otherwise noted. All incubations were carried out in a final volume of $1 \mathrm{ml}$ of culture medium in $12 \times 75-\mathrm{mm}$ glass tubes, $5 \% \mathrm{CO}_{2}, 37^{\circ} \mathrm{C}$ on a rocker platform. Upon completion of the incubation, the tubes were centrifuged $(800 \mathrm{~g}, 10 \mathrm{~min})$ and $0.5 \mathrm{ml}$ of the culture medium was counted. A cytotoxic index was then calculated as: [(dpm released in the presence of effector cells) - (spontaneous dpm released in the absence of effector cells)]/[(dpm in supernates of target cells disrupted by $1 \%$ triton-X detergent) - (spontaneous dpm released in the absence of effector cells)]. All studies were performed in duplicate and no study was accepted if the spontaneous release of $\mathrm{dpm}$ in the absence of effector cells was $>30 \%$ of the $\mathrm{dpm}$ released in the presence of Triton-X.

To evaluate whether eosinophil cytotoxicity requires the presence of intact cells, cytotoxicity experiments were performed with eosinophil sonicates and culture supernates. Eosinophils $\left(10^{6}\right)$ were mechanically disrupted by sonication or were cultured for $24 \mathrm{~h}$ in RPMI-1640 with $10 \%$ fetal calf serum to generate culture supernates. The cytotoxicity of the sonicates and culture supernates was then compared with the cytotoxicity mediated by intact eosinophils. To evaluate the possibility that eosinophil cytotoxicity was mediated through oxidant mechanisms, eosinophils were incubated with HFL-1 fibroblasts in the presence of superoxide dismutase $(300 \mathrm{U} / \mathrm{ml})$, catalase $(3,000 \mathrm{units} / \mathrm{ml})$, and dimethyl sulfoxide (DMSO; $0.1 \%$ ), all three were from Sigma Chemical Co. To evaluate whether the eosinophil cytotoxicity could be augmented by stimulants, eosinophils were incubated in the presence of eosinophil chemotactic factor (ECF-A, Val-Gly-Ser-Glu, Vega Biochemicals, $10^{-4}$ M), phorbol myristate acetate (PMA, Sigma Chemical Co., $100 \mathrm{ng} / \mathrm{ml}$ ), and histamine (free base, Sigma Chemical Co., $10^{-4} \mathrm{M}$ ).

To compare the cytotoxic effector functions of lung eosinophils to alveolar macrophages, macrophages were recovered from normal individuals by bronchoalveolar lavage as previously described. Equivalent numbers of lung eosinophils and alveolar macrophages were then tested against AK-D cells as described above.

Statistical evaluation. All data are presented as mean \pm SEM and all comparisons between groups are made using a two-tailed $t$ test.

\section{Results}

Eosinophils in the lower respiratory tract in the interstitial lung disorders. Eosinophils are frequent participants in the alveolitis of chronic interstitial lung disorders, and occasionally the mag- 
nitude of the eosinophil contribution is quite marked. In 680 consecutive bronchoalveolar lavages of these disorders, eosinophils comprised $5 \%$ or more of the recovered lavage cells in $20 \%$ of all lavage analyses (Fig. 1). In contrast, eosinophils were rarely present in lavage analyses of normal individuals. Eosinophils represented $<1 \%$ of all cells recovered in $95 \%$ of all normals (111 of 117 subjects) and <4\% in the other 5\% (6 of 117) of the normal population. Interestingly, eosinophils were found to represent $>5 \%$ of all effector cells present in several disorders not classically considered as "eosinophilic disorders" such as IPF (33\% of lavage procedures of IPF patients; $44 \%$ of all IPF patients), sarcoidosis (7\% of all lavage procedures of sarcoid patients; $14 \%$ of all sarcoid patients), hypersensitivity pneumonitis (HyPx; $10 \%$ of all lavage procedures in $\mathrm{HyPx}$ patients; $17 \%$ of all HyPx patients) and the collagen-vascular disorders (CVDx; $20 \%$ of all lavage procedures of CVDx patients, $26 \%$ of all CVDx patients). In addition, eosinophils were frequently found in lavage analyses of disorders generally considered to be pulmonary eosinophilic inflammatory diseases, such as histiocytosis-X (HX; $15 \%$ of all lavage procedures of $\mathrm{HX}$ patients; $15 \%$ of all HX patients) and chronic eosinophilic pneumonia (EPx; $36 \%$ of all lavage procedures of EPx patients; $25 \%$ of all EPx patients).

Connective tissue-specific proteases derived from eosinophils. Guinea pig eosinophil granule extract contained no detectible elastase or nonspecific neutral protease activity (Fig. 2). In contrast, in a granule extract prepared from equivalent numbers of human neutrophils, elastase and nonspecific neutral protease activity were readily detectible.

Guinea pig eosinophil granule extract did contain collage-

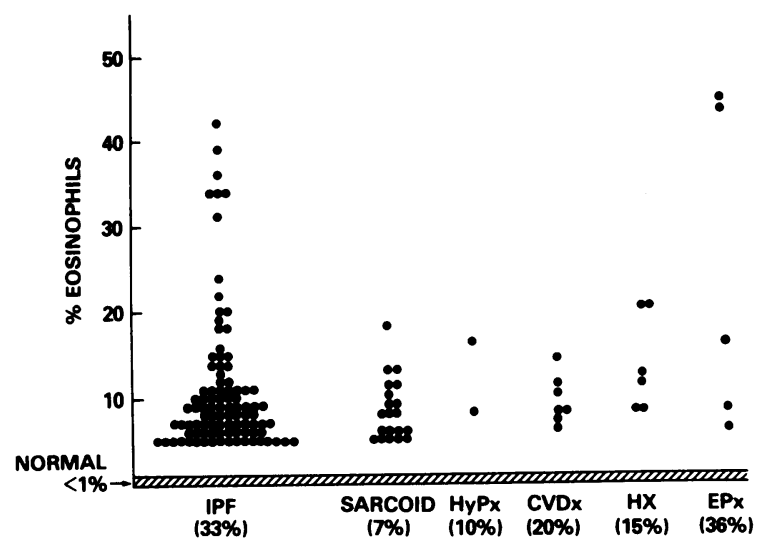

Figure 1. The frequency with which eosinophils participate in the alveolitis of various interstitial lung diseases. Eosinophils comprised $>5 \%$ of the recovered lavage cells in $20 \%$ (136) of 680 studies of patients with interstitial disease. In contrast, eosinophils comprised $<1 \%$ of recovered lavage cells in $95 \%$ of normal subjects (hatched area). Data is presented only for those individuals in whom eosinophils represented $>5 \%$ of recovered effector cells. Brackets under each group represent the proportion of lavage analyses in each group in which eosinophils represented $>5 \%$ of cells recovered.
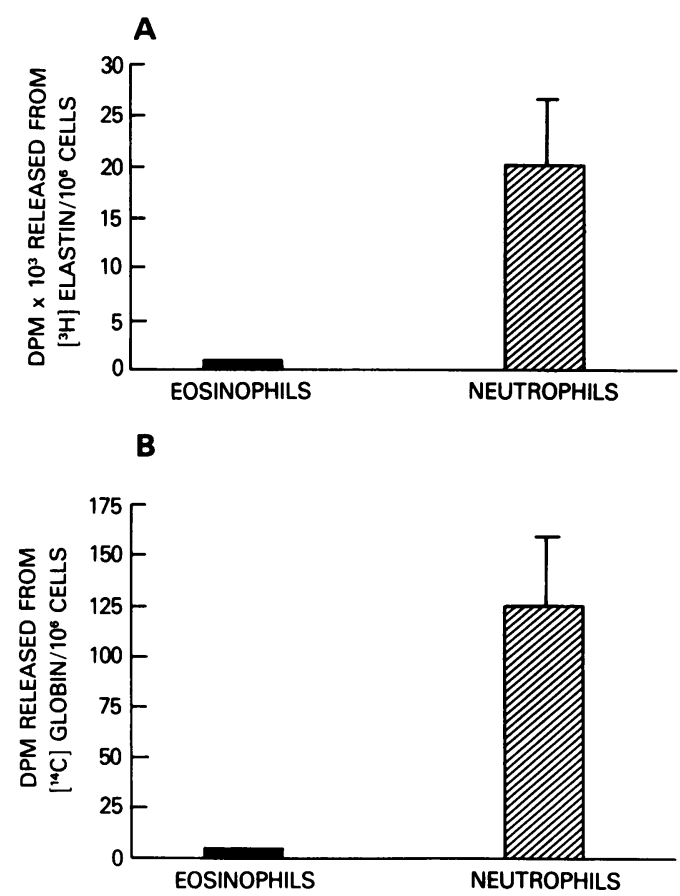

Figure 2. Comparison of guinea pig eosinophils and human peripheral blood neutrophils for the presence of $(A)$ elastase and $(B)$ nonspecific neutral protease activity. Data are presented for four replicate experiments. While neutrophil granule extract contained readily detectible amounts of both proteases, neither was detectible in the eosinophil granule extract.

nase, but it was not active until it was "activated" with trypsin (Fig. 3). While the eosinophil extracts did not cleave human type I or type III collagen when incubated with these substrates alone, when the granule extract was "activated" by trypsin and then incubated with the collagen substrates, collagenase-specific breakdown products $\left(\mathrm{TC}_{\mathrm{A}}\right.$ and $\left.\mathrm{TC}_{\mathrm{B}}\right)$ were detected. No collagen breakdown was detected in control experiments in which trypsin alone, soybean trypsin inhibitor alone, or both, were incubated with collagen (data not shown). To prove that the collagenase was derived from the eosinophils, guinea pig peritoneal macrophages (the principal contaminating cell of the guinea pig eosinophil preparations) were sonicated and incubated with collagen. No active or latent (trypsin activation) collagenase activity was present in the macrophage sonicates (data not shown).

The guinea pig eosinophil collagenase demonstrated the inhibitory profile typical of most vertebrate collagenases (Fig. 4). While both the type I and type III collagenase activity was inhibited by EDTA, it was not inhibited by PMSF or $\alpha 1$-antitrypsin.

Human eosinophil granule extract also contained collagenase activity against type I and type III collagen (Fig. 5). However, in contrast to the guinea pig eosinophil collagenase, the human enzyme was active as isolated and did not require pretreatment with trypsin. Unfortunately, because of the small number of 

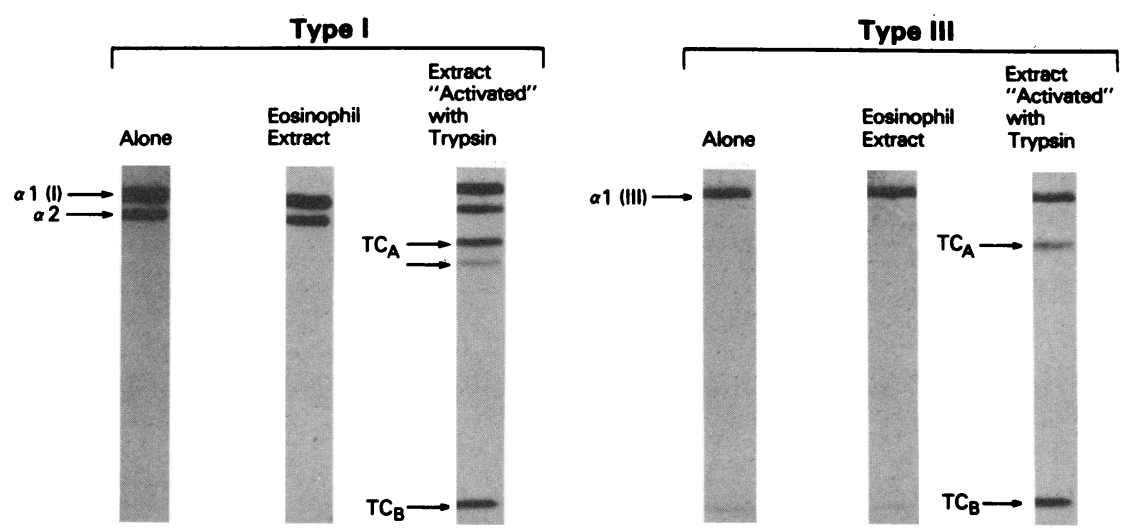

Figure 3. Autoradiograms of sodium dodecyl sulfate (SDS)-polyacrylamide gel analysis of guinea pig eosinophil granule extract for the presence of active and "latent" collagenase activity. (Left) Human lung type I collagen substrate. Incubation of eosinophil granule extract with $\left[{ }^{3} \mathrm{H}\right]$ type I collagen $\left(24 \mathrm{~h}, 22^{\circ} \mathrm{C}\right)$ did not result in cleavage of the substrate. In contrast, incubation of eosinophil granule extract with trypsin resulted in activation of an eosinophil collagenase yielding $\mathrm{TC}_{\mathrm{A}}$ and $\mathrm{TC}_{\mathrm{B}}$ collagenase-specific breakdown products. The arrows indicating $\alpha 1(\mathrm{I})$ and $\alpha 2$ refer to the intact type I collagen component polypeptides. (Right) Human lung type III collagen substrate. Incubation of the eosinophil granule extract with $\left[{ }^{3} \mathrm{H}\right]$ type III collagen did not result in cleavage of the substrate. Incubation with trypsin uncovered a "latent" type III collagenase. The intact polypeptide is indicated as $\alpha 1$ (III) and the collagenase specific products as $\mathrm{TC}_{\mathrm{A}}$ and $\mathrm{TC}_{\mathrm{B}}$.

A

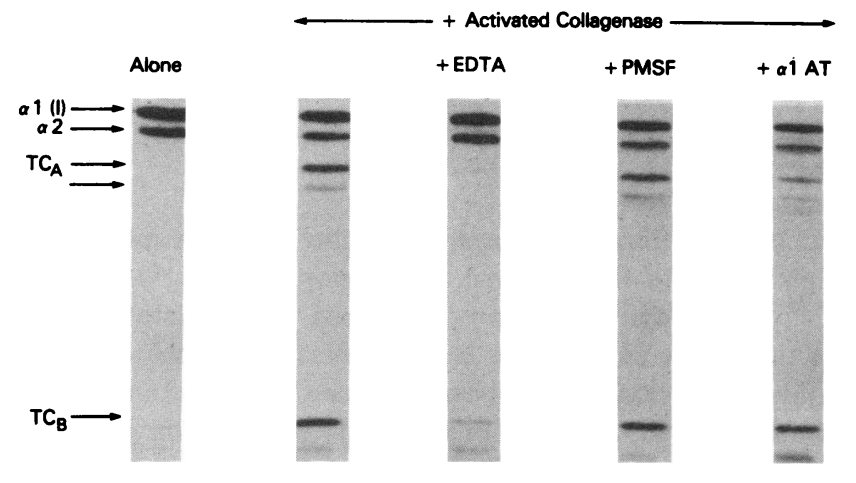

$\mathbf{B}$

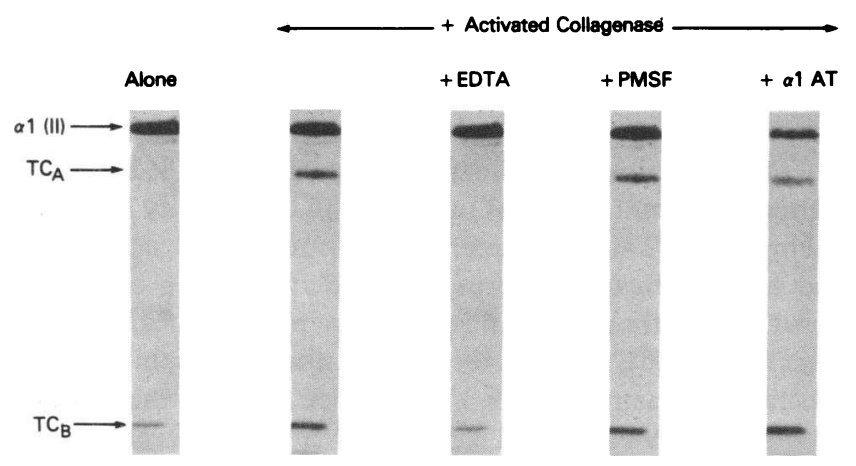

Figure 4. Inhibitory profile of the guinea pig eosinophil collagenase. $(A)$ Type I collagen. Eosinophil collagenase activity was inhibited by EDTA but not by PMSF or by $\alpha 1$-antitrypsin. (B) Type III collagen. Eosinophil collagenase activity was inhibited by EDTA but not by PMSF or $\alpha 1$-antitrypsin. Arrows indicate the intact polypeptides $(\alpha 1[I], \alpha 2$ for type I; $\alpha 1$ [III] for type III) and the collagenase specific breakdown products $\left(\mathrm{TC}_{\mathrm{A}}, \mathrm{TC}_{\mathrm{B}}\right)$. human eosinophils available, it was not possible to determine if this was because the human eosinophil collagenase was active within the granules in situ or whether it was activated during the preparation process. Although there were small proportions $(9 \%)$ of neutrophils in the human eosinophil preparation used for these studies, three lines of evidence suggested that the neutrophils played no role. First, the human eosinophil granule extract represented the lysosomal contents of $60 \times 10^{6}$ leukocytes/ml ( $91 \%$ eosinophils, $9 \%$ neutrophils). To estimate the possible protease contamination from these contaminating neutrophils, neutrophil granule extract was diluted to yield a final preparation that represented $\sim 6 \times 10^{6}$ neutrophils, which is the equivalent number of neutrophils contaminating the eosinophil preparation (i.e., $10 \%$ of $60 \times 10^{6}$ leukocytes). Under the

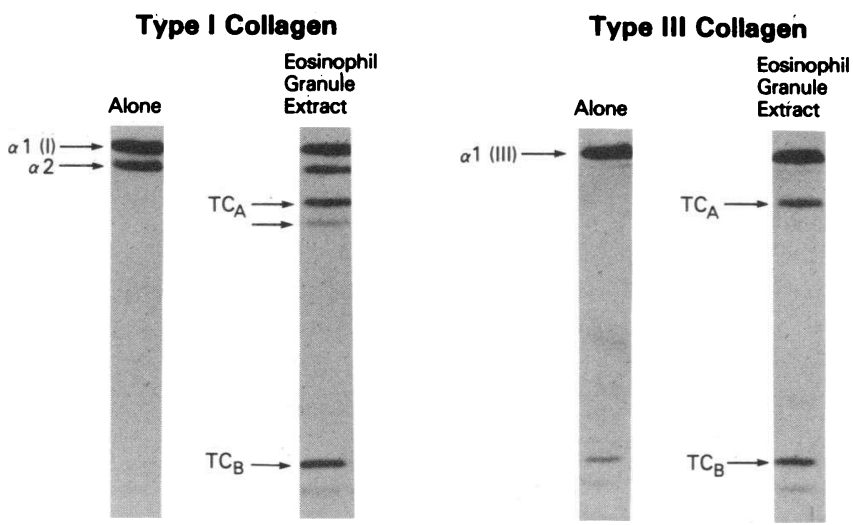

Figure 5. Autoradiograms of SDS-polyacrylamide gel analysis of human peripheral blood eosinophil granule extract for the presence of collagenase. Human eosinophil granule extract contained an active collagenase with activitý against both type I and type III collagen. Arrows indicate the intact polypeptides ( $\alpha 1[1], \alpha 2$ for type I; $\alpha 1[I I I]$ for type III) and the collagenase specific breakdown products $\left(\mathrm{TC}_{\mathrm{A}}\right.$, $\mathrm{TC}_{\mathrm{B}}$. 
conditions used, no collagenase activity could be detected in the granule extracts from this number of neutrophils (data not shown). Second, the collagenase present in the human eosinophil preparation cleaved both type I and type III collagen, while human neutrophil collagenase preferentially cleaves type I (33). Third, the type III collagenase activity was not inhibited by either PMSF or $\alpha 1$-antitrypsin, inhibitors of human neutrophil elastase, an enzyme capable of cleaving type III collagen $(38,39)$.

Eosinophil cytotoxicity for lung parenchymal cells. Guinea pig eosinophils exhibited spontaneous cellular cytotoxicity for human lung fibroblasts after $24 \mathrm{~h}$ of incubation (Fig. 6). Eosinophil-mediated killing increased directly with increasing effector-to-target cell ratios, and significant cytotoxicity was present at effector-to-target cell ratios of 40:1 and 80:1. Since separate experiments had shown that other effector cells (human alveolar macrophages and human peripheral blood mononuclear cells) did not kill fibroblasts at similar effector-to-target cell ratios (data not shown), the cytotoxicity mediated by eosinophils in these experiments could not be explained by "nonspecific" mechanisms such as depletion of substrate in the media by excess numbers of effector cells.

Not only were the eosinophils cytotoxic for HFL-1 fibroblasts, but also for lung epithelial cells and mesothelial cells (Fig. 7). Eosinophil cytotoxicity for all three lung parenchymal cells increased with increasing incubation time. Furthermore, under identical conditions, the epithelial cells were significantly more sensitive to eosinophil-mediated killing than the fibroblasts or mesothelial cells ( $P<0.01$, both comparisons).

The cytotoxicity caused by the guinea pig peritoneal eosinophils was "spontaneous" i.e., no stimulus was necessary to

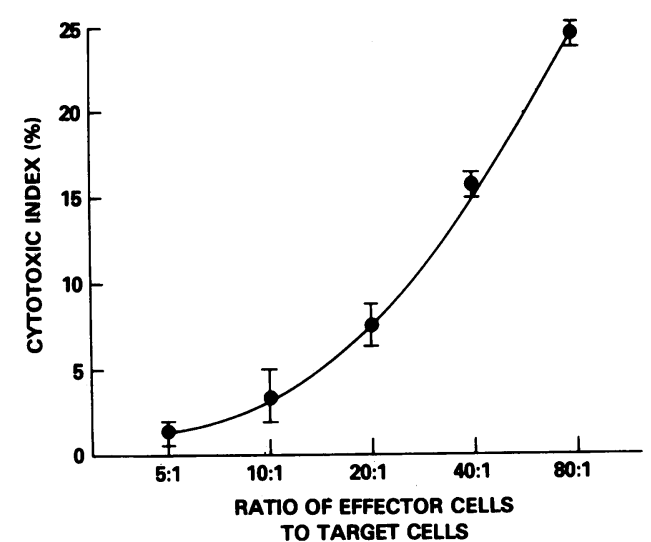

Figure 6. Cytotoxicity of purified guinea pig eosinophils for $\left[{ }^{3} \mathrm{H}\right]$ uridine labeled human fetal lung (HFL-1) fibroblasts. Confluent cultures of fibroblasts were labeled with $\left[{ }^{3} \mathrm{H}\right]$ uridine for $12 \mathrm{~h}$, trypsinized, washed to remove nonincorporated isotope, and counted. The number of fibroblast target cells $\left(2.5 \times 10^{4}\right)$ was held constant while the eosinophil numbers were adjusted to produce various effector-totarget cell ratios. Cytotoxicity for fibroblasts was directly related to the effector-to-target cell ratio.

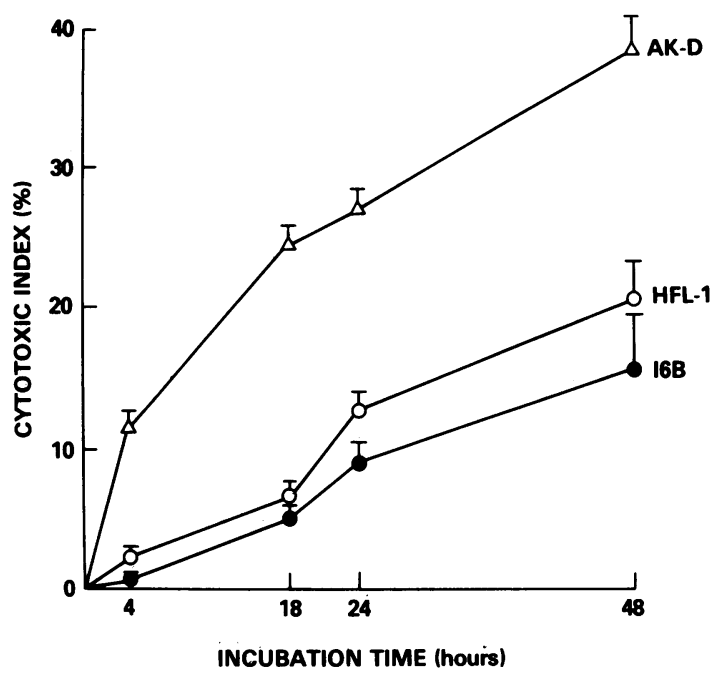

Figure 7. Eosinophil cytotoxicity for three different lung parenchymal cells (AK-D, feline lung epithelial cells; HFL-1, human fetal lung fibroblasts; and 16B, rat pleural mesothelial cells). Eosinophils were cytotoxic for all three lung cell strains $\left(24 \mathrm{~h}, 37^{\circ} \mathrm{C}\right)$ at effector-to-target cell ratios of 40:1. AK-D cells were more sensitive to eosinophil-mediated killing than HFL-1 and I6B cells.

induce the eosinophils to injure the target cells. The most likely explanation for this was that the eosinophils were "activated" in vivo, probably by the processes used to stimulate their attraction to the peritoneum. In this context, attempts to further stimulate the eosinophils were unsuccessful. For example, the addition of ECF-A, PMA, or histamine to the eosinophils had little effect on the eosinophil mediated (cytotoxicity) to the HFL1 target cells as compared with eosinophils alone (Table I; $P$ $>0.1$, all comparisons).

Two lines of evidence suggested that at least part of the mechanism by which eosinophils mediate cytotoxicity to these lung parenchymal cells is by the release of toxic oxidant radicals (Table I). First, the cytotoxicity was partially inhibited by antioxidants. The antioxidants catalase $(10.7 \pm 0.9-4.4 \pm 1.0, P$ $<0.001)$ and dimethyl sulfoxide $(10.7 \pm 0.9-7.9 \pm 0.8, P<0.03)$ caused significant decreases in eosinophil cytotoxicity for HFL1 fibroblasts (Table I). Superoxide dismutase did not inhibit and actually increased eosinophil-mediated killing of HFL-1 fibroblasts. Although the increases were not statistically significant $(P>0.05)$, the increases suggest that eosinophils are releasing significant amounts of superoxide anion in this system. Second, neither eosinophil sonicates or culture supernates were cytotoxic for HFL-1 fibroblasts, i.e., the intact cell was needed; this suggests that a preformed mediator was not involved (Table I). Thus, at least for the number of intact eosinophils needed to cause cytotoxicity, cytosol contents were insufficient to cause equivalent injury. Likewise, if the mediator was present in the culture supernates, it was present in insufficient amounts or was too ephemeral to be detected. 
Table I. Evaluation of Factors that Influence Eosinophilmediated Cytotoxicity for Lung Parenchymal Cells*

\begin{tabular}{lc}
\hline Condition & Cytotoxic index \\
\hline Antioxidants & \\
$\quad$ Eosinophils alone & $10.7 \pm 0.9$ \\
$\quad$ +Superoxide dismutase & $12.7 \pm 0.6(+18.7 \%) \ddagger$ \\
$\quad$ +Catalase & $4.4 \pm 1.0(-58.9 \%) \pi$ \\
$\quad$ +Dimethyl sulfoxide & $7.9 \pm 0.8(-26.2 \%)^{* *}$ \\
Stimulants & \\
Eosinophils alone & $11.8 \pm 1.8$ \\
$\quad$ +ECF-A & $13.3 \pm 1.5(+12.7 \%)$ \\
$\quad$ +PMA & $7.2 \pm 1.9(-39.0 \%)$ \\
$\quad$ +Histamine & $10.4 \pm 1.2(-11.9 \%)$ \\
Other & \\
Eosinophils alone & $15.6 \pm 0.6$ \\
Eosinophils sonicates $\$$ & $1.2 \pm 0.8(-92.3 \%) \pi$ \\
Eosinophil supernates & $3.0 \pm 0.9(-80.8 \%) \pi$ \\
\hline
\end{tabular}

* Guinea pig eosinophils were used as effector cells and human lung fibroblasts (HFL-1) as targets; the effector-to-target ratio was 40:1; all incubations were for $24 \mathrm{~h}, 37^{\circ} \mathrm{C}$.

$\ddagger \%$ increase $(+)$ or decrease $(-)$ from eosinophils alone.

$\S$ Sonicates of $10^{6}$ eosinophils incubated with $2.5 \times 10^{4}$ HFL-1 cells, $24 \mathrm{~h}, 37^{\circ} \mathrm{C}$.

" $10^{6}$ Eosinophils cultured in assay medium for $24 \mathrm{~h}, 37^{\circ} \mathrm{C}$. After centrifugation to remove cells, the culture supernates were incubated with $2.5 \times 10^{4} \mathrm{HFL}-1$ cells, $24 \mathrm{~h}, 37^{\circ} \mathrm{C}$.

I Significantly different from eosinophils alone, $P<0.001$.

** Significantly different from eosinophils alone, $P<0.03$.

Like the guinea pig eosinophils, human bronchoalveolar lavage eosinophils were cytotoxic for AK-D lung cells (Fig. 8). In contrast, normal human alveolar macrophages failed to injure AK-D lung epithelial cells. Insufficient numbers of the lung eosinophils were available to evaluate any of the processes involved in this killing.

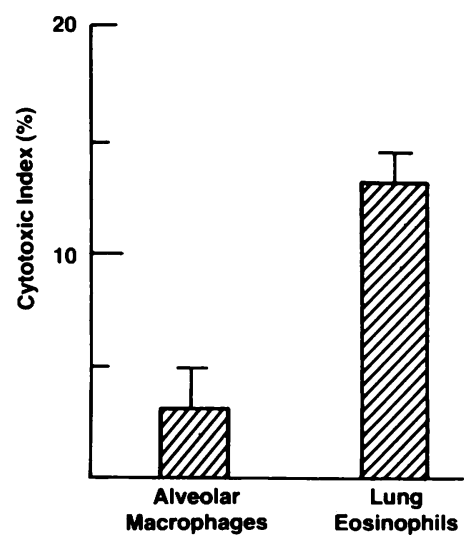

Figure 8. Assessment of the cytotoxic potential of lung eosinophils purified from the human lung. Eosinophils recovered by lavage were purified and then incubated with AK-D lung epithelial cells $\left(24 \mathrm{~h}, 37^{\circ} \mathrm{C}\right)$ at an effector-to-target ratio of $40: 1$. Lung eosinophils, but not alveolar macrophages of a normal individual, were cytotoxic for the AK-D epithelial cells.

\section{Discussion}

Although eosinophils are rarely found in the normal human lower respiratory tract, evaluation of 680 bronchoalveolar lavage analyses in 251 patients with interstitial lung disease demonstrated that eosinophils represented $>5 \%$ of the effector cells of the lower respiratory tract $20 \%$ of the time, with eosinophils occasionally representing $>30 \%$ of all effector cells present. In addition, the present study suggests that eosinophils may play a role in the damage to the parenchymal cells and connective tissue matrix that characterizes these disorders. Evaluation of granules isolated from eosinophils demonstrated the presence of a collagenase capable of cleaving collagen types I and III. Furthermore, eosinophils exhibited spontaneous cytotoxicity for lung epithelial cells, fibroblasts, and mesothelial cells. Thus, while the eosinophil may play a beneficial role in the upper respiratory tract by virtue of its ability to dampen immediate hypersensitivity processes, when it is present in the lower respiratory tract, it may cause significant damage through its proteolytic and cytotoxic potential.

Eosinophilia in the chronic interstitial lung disorders. Although eosinophils are prominent components of the effector cell populations of the upper airways, eosinophils are rarely found in the normal human lower respiratory tract. In addition to the bronchoaveolar lavage analyses in the present study, as well as those of prior studies by us $(3-5,10)$ and other investigators $(40,41)$, light and electron microscopic studies have shown there are only rare eosinophils within the normal human alveolar wall or on the epithelial surface of the lower respiratory tract (42). Furthermore, analysis of the effector cell populations obtained by mechanical disruption of the human lung parenchyma, a technique that samples both the interstitial and epithelial surface compartment, also demonstrates that eosinophils are rarely present $(43,44)$.

In contrast to normal lung, many inflammatory disorders of the lower respiratory tract are associated with an accumulation of eosinophils in the parenchyma. Furthermore, biopsy and autopsy studies have clearly shown that these eosinophils also accumulate in the lung parenchyma independent of blood eosinophilia (6-8). The technique of bronchoalveolar lavage permits quantification of this localized eosinophilia. The present study, and the studies of Reynolds et al. (3), Weinberger et al. (4), and Haslam et al. (9) demonstrate that eosinophilia of the lower respiratory tract is relatively common, and can be extensive. Interestingly, although histiocytosis-X (45) and chronic eosinophilic pneumonia (8) are recognized to be disorders characterized by eosinophilia of the lower respiratory tract, it is clear that IPF, sarcoidosis, hypersensitivity pneumonitis, and the chronic interstitial disease associated with the collagen-vascular disorders can, on occasion, also be characterized by an accumulation of significant numbers of eosinophils in the alveolar structures. Although it is theoretically possible that these lavage cell analyses do not accurately reflect the degree of eosinophilic inflammation in the lower respiratory tract as determined by open lung biopsy, this seems unlikely in view of previous studies 
that show that the types of lung effector cells recovered by bronchoalveolar lavage are quantitatively similar to the types of cells recovered by mechanical disruption of lung biopsy specimens $(43,44)$.

The mechanisms that mediate the accumulation of eosinophils in the lower respiratory tract in these disorders are unknown. However, it is known that the human lower respiratory tract can be a source of factors selectively chemotactic for eosinophils. For example, when stimulated with IgE, fragments of human lung parenchyma release histamine (46), eosinophil chemotactic factor of anaphylaxis $(47,48)$, and other chemotactic polypeptides (49). In this regard, increased amounts of histamine are found in bronchoalveolar lavage fluid of patients with IPF (50). Furthermore, morphologic studies by Kawanami et al. (51) have shown that the density of mast cells in the alveolar walls is enhanced 18-fold in these disorders, and thus it is possible to hypothesize that mast cell products, such as 11,12 , and 15 hydroxy-5,8,10,14-eicosatetraenoic acid (HETE) and prostaglandin $\mathrm{D}_{2}$, may play some role (52-54). In addition, in active IPF, the alveolar macrophages release neutrophil chemotactic factor, which attracts eosinophils, albeit to a far lesser extent than neutrophils $(55,56)$. Complement components are present in the lower respiratory tract and may also play some role (3, $5,57)$.

Although there is only minimal information available that relates the degree of lung eosinophilia to the clinical outcome of interstitial lung disease, recent studies have suggested that increased numbers of lung eosinophils may have prognostic significance. In this context, Haslam et al. (9) have found that patients with IPF with increased numbers of lung eosinophils and/or lung neutrophils respond poorly to treatment while patients with increased numbers of lung lymphocytes have a better response to therapy.

Connective tissue specific proteases carried by eosinophils: The present study demonstrates that the granules of guinea pig and human eosinophils contain a collagenase capable of specifically cleaving human lung collagens type I and III. The observations are consistent with that of Basset et al. (58) who found that homogenates of rat eosinophils were capable of cleaving a labeled mixture of chick and rat skin collagen reconstituted as gels of collagen fibrils. They are also consistent with those of Hibbs et al., (59) who have also recently noted that extracts of guinea pig eosinophils cleaved collagen type I and III.

The evidence gathered to date suggests that eosinophil collagenase is a classic vertebrate collagenase that, like skin and tadpole collagenases, is a metalloenzyme that cleaves collagen types I and III at approximately equal rates $(33,60,61)$. This distinction is important for the human lower respiratory tract where collagenases derived from other inflammatory cells can be present, including that from alveolar macrophages (62) and, in interstitial lung disorders such as IPF, neutrophils (63). While the known properties of the human alveolar macrophage collagenase do not allow it to be distinguished from the eosinophil collagenase (e.g., it also cleaves collagenase I and III and is a metalloenzyme) the neutrophil collagenase (also a metalloen- zyme) specifically cleaves type I collagen at much greater rate than type III (33). Thus, in evaluating the relative contributions to connective tissue damage in the lower respiratory tract in the interstitial disorders, it should be possible to distinguish neutrophil collagenase from the collagenases derived from the eosinophil and alveolar macrophage.

Like many other vertebrate collagenases, the guinea pig eosinophil collagenase is present in an inactive form that can be activated by the nonspecific neutral protease trypsin. The mechanism of this activation is not clear. There is evidence that protease activation of so-called "latent" collagenase reflects removal of a precursor peptide from the molecule, removal of an inhibitor, activation of other activating systems, or changes in conformation of the enzyme $(64,65)$. In reference to collagenases released from inflammatory cells in the human lung, it is known that the rabbit alveolar macrophage can release a neutral protease that can activate rabbit macrophage collagenase (32). Interestingly, the collagenase isolated from human eosinophils did not require activation. However, because of the limitation in the numbers of cells available, it was not possible to determine if this was the true form of the enzyme in the human eosinophil granules or was due to "activation" during the isolation process.

Unlike the alveolar macrophage or neutrophil, the eosinophil has no detectable elastase or nonspecific neutral protease capable of cleaving denatured globin. Thus, while the eosinophil clearly has proteolytic potential to cleave collagen, it does not have the broadly based proteolytic armamentarium of the neutrophil. This observation may help to explain, at least in part, why interstitial lung disorders characterized by a dominance of eosinophils in the alveolitis (such as chronic eosinophilic pneumonia) leave little permanent parenchymal damage if treated promptly (8), while interstitial lung disorders that are usually characterized by a dominance of neutrophils in the alveolitis (such as IPF) are almost always associated with significant permanent derangements of the lower respiratory tract (10).

Cytotoxic effector function of eosinophils. Eosinophils isolated from guinea pig peritoneal exudates and the human lower respiratory tract in chronic interstitial lung disease demonstrate spontaneous cytotoxic capacity for lung parenchymal cells. While it is recognized that eosinophils can destroy parasites such as Shistosoma mansoni $(11,12)$ and that eosinophils can mediate antibody-dependent killing $(19,20)$, the potential for eosinophils to nonspecifically mediate significant injury to normal tissue cells has not been recognized. Interestingly, Parrillo and Fauci (19) did note that human eosinophils exhibit low level cytotoxicity against human heart cells and Chang liver cells, but this was only found at very high effector-to-target ratios (100:1) and only represented minor increases over background injury. In contrast, guinea pig peritoneal eosinophils and human lung eosinophils caused significant cytotoxicity to cat lung epithelial cells at effector-to-target ratios of 40:1. These observations suggest that the potential for eosinophils to injure normal parenchymal cells may be highly dependent on the target cell. In this context, it is very relevant that the lung is a primary "target" for eosinophilia-related organ dysfunction (66), i.e., lung parenchymal 
cells, particularly epithelial cells, may be among cells in the human body that are sensitive to eosinophil mediated injury.

The mechanisms by which eosinophils can injure lung parenchymal cells are not entirely clear, but since antioxidants suppress a significant amount of the injury, it is likely that reactive oxidant species are involved. In this context, eosinophils can generate superoxide anion and hydrogen peroxide and contain a peroxidase, which, in the presence of $\mathrm{H}_{2} \mathrm{O}_{2}$ and a halide, can generate a potent oxidant (21-23). In concert with the concept that eosinophilic cytotoxic damage to the human lung may be mediated by oxidant mechanisms, Cantin et al. (67) have recently noted that the human lung parenchyma is relatively deficient in intracellular antioxidants such as catalase and glutathione peroxidase; i.e., the cells comprising the parenchyma cannot easily defend against a local oxidant burden. In this context, it is relevant that the pulmonary eosinophilic syndromes are the most frequently recognized forms of tissue eosinophilia (66).

\section{References}

1. Beeson, P. B., and D. A. Bass. 1977. The eosinophil. In Major Problems in Internal Medicine. L. N. Smith, Jr., editor. W. B. Saunders Co., Philadelphia. Vol. XIV.

2. Ottesen, E. 1976. Eosinophilia and the lung. In Immunologic and Infectious Reactions in the Lung. C. H. Kirkpatrick and H. Y. Reynolds, editors. Marcel Dekker, Inc., New York. 289-332.

3. Reynolds, H. Y., J. D. Fulmer, J. A. Kazmierowski, W. C. Roberts, M. M. Frank, and R. G. Crystal. 1977. Analysis of broncho-alveolar lavage fluid from patients with idiopathic pulmonary fibrosis and chronic hypersensitivity pneumonitis. J. Clin. Invest. 59:165-175.

4. Weinberger, S. E., J. A. Kelman, N. A. Elson, R. C. Young, Jr., H. Y. Reynolds, J. D. Fulmer, and R. G. Crystal. 1978. Bronchoalveolar lavage in interstitial lung disease. Ann. Intern. Med. 89:459-466.

5. Hunninghake, G. W., J. E. Gadek, O. Kawanami, V. J. Ferrans, and R. G. Crystal. 1979. Inflammatory and immune processes in the human lung in health and disease: evaluation by bronchoalveolar lavage. Am. J. Pathol. 97:149-206.

6. Crofton, J. W., J. L. Livingstone, N. C. Aswarld, and A. T. V. Roberts. 1952. Pulmonary eosinophilia. Thorax. 7:1-35.

7. Liebow, A. A., and C. B. Carrington. 1969. The eosinophilic pneumonias. Medicine (Baltimore). 48:251-285.

8. Carrington, C., W. Addington, A. Goff, I. Madoff, A. Marks, J. Schwaber, and E. Gaensler. 1969. Chronic eosinophilic pneumonia. $N$. Engl. J. Med. 280:787-798.

9. Haslam, P. L., C. W. Turton, A. Lukoszek, H. A. Salsbury, A. Dewar, J. V. Collins, and M. Turner-Warwick. 1980. Bronchoalveolar lavage fluid cell counts in cryptogenic fibrosing alveolitis and their relation to therapy. Thorax. 35:328-339.

10. Crystal R. G., J. E. Gadek, V. J. Ferrans, J. D. Fulmer, B. R. Line, and G. W. Hunninghake. 1981. Interstitial lung disease: current concepts of pathogenesis, staging, and therapy. Am. J. Med. 70:542568.

11. Butterworth, A. E., R. F. Sturrock, V. Houba, and P. H. Rees. 1974. Antibody-dependent cell-mediated damage to schistosomula in vitro. Nature (Lond.) 252:503-505.

12. Butterworth, A. E., H. G. Remold, V. Houba, J. R. David, D. Franks, P. H. David, and R. F. Sturrock. 1977. Antibody-dependent eosinophil-mediated damage to ${ }^{51} \mathrm{Cr}$-labelled schistosomula of Schis- tosoma mansoni: mediation by IgG, and inhibition by antigen-antibody complexes. J. Immunol. 118:2230-2236.

13. Kazura, J. W., and D. I. Grove. 1978. Stage-specific antibodydependent eosinophil-mediated destruction of Trichinella spiralis. Nature (Lond.). 274:588-589.

14. Gleich, G. J., D. A. Loegering, and J. E. Maldonado. 1973. Identification of a major basic protein from guinea pig eosinophil granules. J. Exp. Med. 137:1459-1471.

15. Gleich, G. J., D. A. Loegering, F. Kueppers, S. P. Bajaj, and K. G. Mann. 1974. Physiochemical and biological properties of the major basic protein from guinea pig eosinophil granules. J. Exp. Med. 140:313-332.

16. Gleich, G. J., E. Frigas, and D. A. Loegering. 1979. Cytotoxic properties of the eosinophil major basic protein. J. Immunol. 123:29252927.

17. Frigas, E., D. A. Loegering, and G. J. Gleich. 1981. Cytotoxic effects of the guinea pig eosinophil major basic protein on tracheal epithelium. Lab. Invest. 42:35-43.

18. Frigas, E., D. A. Loegering, G. O. Solley, G. M. Farrow, and G. J. Gleich. 1981. Elevated levels of the eosinophil major basic protein in the sputum of patients with bronchial asthma. Mayo Clin. Proc. 56:345-353.

19. Parrillo, J. E., and A. S. Fauci. 1978. Human eosinophils. Purification and cytotoxic capability of eosinophils from patients with the hypereosinophilic syndrome. Blood. 5:457-473.

20. Sanderson, C. J., and J. A. Thomas. 1978. A comparison of the cytotoxic activity of eosinophils and other cells by ${ }^{51}$ chromium release and time lapse microcinematography. Immunology. 34:771-780.

21. Dechatelet, L. R., R. A. Migler, P. S. Shirley, D. A. Bass, and C. E. McCall. 1978. Enzymes of oxidative metabolism in the human eosinophil. Proc. Soc. Exp. Biol. Med. 158:537-541.

22. Henderson, W. R., E. Y. Chi, and S. J. Klebanoff. 1980. Eosinophil peroxidase-induced mast cell secretion. J. Exp. Med. 152:265-279.

23. Klebanoff, S. J., E. C. Jong, and W. R. Henderson, Jr. The eosinophil peroxidase: purification and biological properties. In The Eosinophil: Chemical, Biochemical, and Functional Aspects. A. Mahmold and K. F. Austen, editors. Grune \& Stratton, Inc., New York. In press.

24. Fauci, A. S., J. B. Harley, and W. C. Roberts. 1982. The idiopathic hypereosinophilic syndrome. Clinical, pathophysiologic, and therapeutic considerations. Ann. Intern. Med. 97:78-92.

25. Keogh, B. A., and R. G. Crystal. 1981. Chronic interstitial lung disease. In Current Pulmonology. D. H. Simmons, editor. Wiley, New York. 3:237-340.

26. Pincus, S. H. 1978. Production of eosinophil-rich guinea pig peritoneal exudates. Blood. 52:127-134.

27. Gleich, G. J., and D. Loegering. 1973. Selective stimulation and purification of eosinophils and neutrophils from guinea pig peritoneal fluids. J. Lab. Clin. Med. 82:523-528.

28. Boyum, A. 1968. Isolation of mononuclear cells and granulocytes from human blood. Scand. J. Clin. Lab. Invest. 21(Suppl. 97):77-89.

29. Hensen, P. M., B. Zanolari, N. Schwartzman, and S. Hong. 1978. Intracellular control of human neutrophil secretion: C5a-induced stimulus-specific desensitization and the effects of cytochalasin $B^{1} . J$. Immunol. 121:851-855.

30. Taylor, J. C., and I. P. Crawford. 1975. Purification and preliminary characterization of human leukocyte elastase. Arch. Biochem. Biophys. 169:91-101.

31. Bielefeld, D. R., R. M. Senior, and S. Y. Yu. 1975. A new method for determination of elastolytic activity using $\left[{ }^{14} \mathrm{C}\right]$-labelled elastin and its application to leukocytic elastase. Biochem. Biophys. Res. Commun. 67:1553-1559. 
32. Horwitz, A. L., J. A. Kelman, and R. G. Crystal. 1976. Activation of alveolar macrophage collagenase by a neutral protease secreted by the same cell. Nature (Lond.). 264:772-774.

33. Horwitz, A. L., A. J. Hance, and R. G. Crystal. 1977. Granulocyte collagenase: selective digestion of type I relative to type III collagen. Proc. Natl. Acad. USA. 74:897-901.

34. Zeijlemaher, W. P., M. T. L. Roos, P. T. A. Schellehens, and V. P. Eijsvoogel. 1975. Antibody-dependent human lymphocytotoxicity: a microassay system. Eur. J. Immunol. 5:579-584.

35. Bradley, K. H., O. Kawanami, V. J. Ferrans, and R. G. Crystal. 1980. The fibroblast of human lung alveolar structures: a differentiated cell with a major role in lung structure and function. In Methods in Cell Biology, C. C. Harris, B. R. Trump, and G. D. Stoner, editors. Academic Press, Inc., New York. 21A:37-64.

36. Elson, N. A., J. B. Karlinsky, J. A. Kelman, R. A. Rhodes, and R. G. Crystal. 1976. Differentiated properties of the type 2 alveolar cell: partial characterization of protein content, synthesis and secretion. Clin. Res. 24:454A. (Abstr.)

37. Thiollet, J., M. D. Jaurand, H. Kaplan, J. Bignon, and E. Hollande. 1978. Culture procedure of mesothelial cells from the rat parietal pleura. Biomedicine (Paris). 29:69-73.

38. Gadek, J. E., G. A. Fells, D. G. Wright, and R. G. Crystal. 1980. Human neutrophil elastase functions as a type III collagen "collagenase." Biochem. Biophys. Res. Commun. 95:1815-1822.

39. Mainardi, C. L., D. L. Hasty, J. M. Seyer, and A. H. Kang. 1980. Specific cleavage of human type III collagen by human polymorphonuclear leukocyte elastase. Biol. Chem. 255:12006-12010.

40. Hoidal, J. R., R. B. Rox, P. A. Lemarbe, R. Perri, and J. E. Repine. 1981. Altered oxidative metabolic responses in vitro of alveolar macrophages from asymptomatic cigarette smokers. Am. Rev. Respir. Dis. 123:85-89.

41. Bell, D. Y., J. A. Haseman, A. Spock, G. McLennan, and G. E. R. Hook. 1981. Plasma proteins of the bronchoalveolar surface of the lungs of smokers and non-smokers. Am. Rev. Respir. Dis. 124:7279.

42. Spencer, H. 1977. Pathology of the lung. H. Spencer, editor W. B. Saunders Co., Philadelphia. 2:15-69.

43. Hunninghake, G. W., O. Kawanami, V. J. Ferrans, R. C. Young, Jr., W. C. Roberts, and R. G. Crystal. 1981. Characterization of the inflammatory and immune effector cells in the lung parenchyma of patients with interstitial lung disease. Am. Rev. Respir. Dis. 123:407412.

44. Haslam, P. L., C. W. G. Turton, and B. Heard. 1980. Bronchoalveolar lavage in pulmonary fibrosis: comparison of cells obtained with lung biopsy and clinical features. Thorax. 35:9-18.

45. Basset, F., B. Corrin, and H. Spencer. 1978. Pulmonary histiocytosis-X. Am. Rev. Respir. Dis. 118:811-819.

46. Clark, R. A. F., J. I. Gallin, and A. P. Kaplan. 1975. The selective eosinophil chemotactic activity of histamine. J. Exp. Med. 142:14621476.

47. Kay, A. B., D. J. Stechschulte, and K. F. Austen. 1971. An eosinophil leukocyte chemotactic factor of anaphylaxis. J. Exp. Med. 133:602-619.

48. Kay, A. B., and K. F. Austen. 1971. The IgE-mediated release of an eosinophil leukocyte chemotactic factor from human lung. $J$. Immunol. 107:899-902.

49. Boswell, R. N., K. F. Austen, and E. J. Goetzl. 1978. Intermediate molecular weight eosinophil chemotactic factors in rat peritoneal mast cells: Immunologic release, granule association, and demonstration of structural heterogeneity. J. Immunol. 120:15-20.
50. Haslam, P. L., O. Cromwell, A. Dewar, and M. Turner-Warwick. 1981. Evidence of increased histamine levels in lung lavage fluids from patients with cryptogenic fibrosing alveolitis. Clin. Exp. Immunol. 44:587-593.

51. Kawanami, O., V. J. Ferrans, J. D. Fulmer, and R. G. Crystal. 1979. Ultrastructure of pulmonary mast cells in patients with fibrotic lung disorders. Lab. Invest. 40:717-734.

52. Goetzl, E. J., J. M. Woods, and R. R. Gorman. 1977. Stimulation of human eosinophil and neutrophil polymorphonuclear leukocyte chemotaxis and random migration by 12-L-hydroxy-5,8,10,14-eicosatetraenoic acid. J. Clin. Invest. 59:179-183.

53. Goetzl, E. J., P. F. Weller, and F. F. Sun. 1980. The regulation of human eosinophil function by endogenous mono-hydroxy-eicosatetraenoic acids (HETEs). J. Immunol. 124:926-933.

54. Goetzl, E. J., P. F. Weller, and F. H. Valone. 1979. Biochemical and functional bases of the regulatory and protective roles of the human eosinophil. Adv. Immunol. 14:157-167.

55. Hunninghake, G. W., J. E. Gadek, T. J. Lawley, and R. G. Crystal. 1981. Mechanisms of neutrophil accumulation in the lungs of patients with idiopathic pulmonary fibrosis. J. Clin. Invest. 68:259-269.

56. Hunninghake, G. W., J. E. Gadek, H. M. Fales, and R. G. Crystal. 1980. Human alveolar macrophage-derived chemotactic factor for neutrophils: stimuli and partial characterization. J. Clin. Invest. 66:473-483.

57. Kay, A. B., H. S. Shi, and K. F. Austen. 1973. Selective attraction of eosinophils and synergism between eosinophil chemotactic factor of anaphylaxis (ECF-A) and a fragment cleaved from the fifth component of complement (C5a). Immunology. 24:969-976.

58. Basset, E. G., J. R. Baker, P. A. Baker, and D. B. Myers. 1976. Comparison of collagenase activity in eosinophil and neutrophil fractions from rat peritoneal exudates. Aust. J. Exp. Biol. Med. Sci. 54:459-465.

59. Hibbs, M. S., C. L. Mainardi, and A. H. Kang. 1982. Typespecific collagen degradation by eosinophils. Biochem. J. 207:621-624.

60. Welgus, H. G., J. J. Jeffry, and A. Z. Eisen. 1981. The collagen substrate specificity of human skin fibroblast collagenase. J. Biol. Chem. 256:9511-9515.

61. Gross, J., and Y. Nagai. 1965. Specific degradation of the collagen molecule by tadpole collagenolytic enzyme. Proc. Natl. Acad. Sci. USA. 54:1197-1204.

62. Gadek, J. E., G. A. Fells, and R. G. Crystal. 1982. Release of collagenase and elastase by human alveolar macrophages is constitutive: implications for the role of the macrophage in generation of proteases in the lung. Fed. Proc. 41:687.

63. Gadek, J. E., J. A. Kelman, G. A. Fells, S. E. Weinberger, A. L. Horwitz, H. Y. Reynolds, J. D. Fulmer, and R. G. Crystal. 1979. Collagenase in the lower respiratory tract of patients with idiopathic pulmonary fibrosis. N. Engl. J. Med. 301:737-742.

64. Woolley, D. E., and J. M. Evanson. 1980. Collagenase in normal and pathological connective tissues. John Wiley \& Sons, Inc., New York.

65. Werb, Z., C. L. Mainardi, C. A. Vater, and E. D. Harris. 1983. Endogenous activation of latent collagenase by rheumatoid synovial cells. Evidence for a role of plasminogen activator. N. Engl. J. Med. 296:1017-1023.

66. Weller, P. F., and E. J. Goetzl. 1980. The human eosinophil Roles in host defense and tissue injury. Am. J. Pathol. 100:793-820.

67. Cantin, A., G. Fells, J. T. Given, W. K. Nichols, and R. G. Crystal. 1983. Sensitivity of the lung to oxidants: cells of the lower respiratory tract are relatively deficient in scavengers of $\mathrm{H}_{2} \mathrm{O}_{2}$. Am. Rev. Respir. Dis. 127:163. 